\title{
U.S. Faculty and Administrators' Experiences and Approaches in the Early Weeks of the COVID-19 Pandemic
}

\author{
Nicole Johnson \\ Research Director, Canadian Digital Learning Research Association \\ George Veletsianos \\ Professor \& Canada Research Chair in Innovative Learning and Technology, \\ Royal Roads University \\ Jeff Seaman \\ Director, Bay View Analytics
}

\begin{abstract}
The COVID-19 pandemic has had a profound and rapid impact on higher education institutions across the world. In this study, we report the findings of a survey investigating the rapid transition to emergency remote teaching in the early weeks of the pandemic at public and private postsecondary institutions in the United States. Participants consisted of 897 faculty and administrators at 672 U.S. institutions. Findings reveal that with few exceptions nearly all reporting institutions transitioned to emergency teaching and learning approaches. Administrators reported that faculty with and without online teaching experience pivoted to online teaching, and nearly all administrators indicated that those who did not have online teaching experience were in the process of learning how to teach online. Regardless of whether faculty had previous experience teaching online or not, many faculty reported that they were using new teaching methods. A majority of faculty reported making changes to their assignments or exams as a result of transitioning to a new mode of delivery. Nearly half reported lowering the expected volume of work for students (including dropping assignments or exams) and/or shifting to a pass/fail model for this semester. The primary areas where faculty and administrators identified a need for assistance related to student support, greater access to online digital materials, and guidance for working from home. This study provides an early snapshot of efforts towards teaching and learning continuity at a large scale and provides some insights for future research and practice.
\end{abstract}

Keywords: COVID-19, online learning, emergency remote teaching, remote teaching, remote learning

Johnson, N., Veletsianos, G., \& Seaman, J. (2020). U.S. faculty and administrators' experiences and approaches in the early weeks of the COVID-19 pandemic. Online Learning, 24(2), 6-21. https://doi.org/10.24059/olj.v24i2.2285 


\section{U.S. Faculty and Administrators' Experiences and Approaches in the Early Weeks of the COVID-19 Pandemic}

At the time of writing, the impact of COVID-19 on institutions of higher education has been widespread. In March of 2020, UNESCO estimated that in the span of two months 850 million individuals have transitioned to alternative forms of teaching and learning worldwide (UNESCO, 2020), following the reduction or elimination of in-person courses to support physical distancing efforts and mitigate the spread of the virus. In this study, we provide one of the first reports of how this transition has impacted institutions, administrators, and faculty in the United States. Specifically, we report the results of a survey that sought to understand the transition to online course delivery in the early weeks of the COVID-19 pandemic. Following a review of literature that identifies classroom and faculty impacts and responses to prior events of similar magnitude, we discuss the methods used in this investigation. Next, we present the findings of this study and discuss their implications for research and practice.

\section{Review of the Relevant Literature}

The COVID-19 pandemic has sent shock waves to the entire higher education system on a global scale. As the virus spread, city-wide, regional, and country-wide lockdown orders were put into place across the world. With stay-at-home orders or physical distancing orders prohibiting larger gatherings, decisions to cancel, postpone, or move in-person classes online came within a matter of days in most countries. Moving education online in times of disruption (e.g., natural disasters or political unrest) is not a new strategy (e.g., Ayebi-Arthur, 2017; Beebe, 2010; Lorenzo, 2008; Swartz, Gachago, \& Belford, 2018); however, in contrast to COVID-19, prior events described regional responses: few disruptions warranted a worldwide, or even nationwide, transition to online/distance education.

Previous studies investigating shifts to online course delivery during crises have offered lessons learned during these times. For instance, the Sloan Semester was an initiative that provided continuity of learning following Hurricane Katrina in which over one hundred institutions provided courses for students in the affected region to maintain their studies. Reflections from participating faculty revealed that the student-to-student interactions and class dialogues in virtual learning environments created an opportunity for students to give and receive emotional support to one another, which was important for student well-being as they dealt with the aftermath of the disaster (Lorenzo, 2008).

In a case study investigating resilience with e-learning in response to the 2011 earthquakes in New Zealand, Ayebi-Arthur (2017) discussed the importance of supporting faculty, noting that the availability of the selected technologies and their ease of use positively influenced the use of e-learning tools. Tull et al. (2017) described effective professional development practices that emerged following the New Zealand earthquakes, particularly shifting from a reliance on face-toface training and one-on-one support to online communities of practice. Similarly, Czerniewicz et al. (2019), in their study of the move to online and blended learning during student protests and university shutdowns in South Africa, noted the importance of maintaining an awareness of student inequities when determining how to shift learning online. They remarked that "blended learning may have helped overcome certain practical hurdles (classroom disruptions) while raising others (digital inequality)" (p. 18). Ultimately, these past studies illustrate that a shift from in-person instruction to online course delivery during a disruptive event requires cognizance of the complex 
needs of staff, administrators, students, and faculty in order to effectively provide instruction and support.

At the time of writing, little published literature existed that specifically examined experiences in the higher education sector with COVID-19. However, between the beginning of the transition in the U.S. (March 2020) to the submission of this paper (May 2020), the topic has been explored in varied ways in the gray literature. Numerous blog posts, editorials, and short reports emerged, highlighting the challenges and anxieties faced by students, faculty, and institutions as they made decisions about whether and how to provide continuity of education as COVID-19 cases continued to rise (e.g., Judy, 2020; Morgan, 2020; Reed, 2020). Topics ranged from how to manage inequities and student needs, how to support faculty teaching online for the first time, sharing faculty and student experiences, and the implications for institutions in both the short and long-term (e.g., Baker, 2020; DePietro, 2020; Govindarajan \& Srivastava, 2020; Grajek, 2020; Veletsianos \& Kimmons, 2020). The gray literature is instructive as it affirms the upheaval in higher education arising from COVID-19, reveals that the impacts for institutions, faculty, and students alike have been pervasive, and highlights experiences "on the ground."

The rapid transition from predominantly in-person classes to delivering classes online has also sparked much discussion within the scholarly community. One significant area of debate surrounds the use of the term "online learning." Bates (2020), emphasized that there are differences between online education and remote education employed rapidly in response to a pandemic. He argues that online learning is more than the mode of delivery, defining online learning as follows: "A form of distance education in which a course or program is intentionally designed in advance to be delivered fully online. Faculty use pedagogical strategies for instruction, student engagement, and assessment that are specific to learning in a virtual environment" (para. 18). Hodges et al. (2020) agree, arguing that the current environment represents "a temporary shift of instructional delivery to an alternate delivery mode due to crisis circumstances [which] involves the use of fully remote teaching solutions for instruction or education that would otherwise be delivered face-to-face or as blended or hybrid courses and that will return to that format once the crisis or emergency has abated" (para. 13). Throughout this paper, we avoid using the term online learning to describe the in-person classes that are now being delivered online. Rather, we use terms that clarify the mode of delivery (e.g., delivering courses online, delivering instruction online) and recognize the context of the pandemic (e.g., emergency remote teaching) that surrounds these efforts.

As U.S. institutions begin to announce plans for the fall of 2020, with some aiming for inperson classes to resume (Burke, 2020; Fain, 2020), understanding the needs and experiences of faculty and administrators early and at a large scale is critical for a variety of reasons. Such research may provide an early snapshot in time informing next steps. Understanding faculty and administrator experiences may enable researchers to gain valuable insights on how individuals responded, informing future course design, institutional responses, support structures for faculty/students/staff, and potentially shed more light on techno-pedagogical practices that emerged during this period. This is the gap that this research addresses. Nonetheless, findings from such studies need to be set in context given the rapidly-shifting landscape that surrounds spring, summer, and fall 2020 education offerings. In this particular study, we sought to understand these experiences at a large-scale through a short survey in the early weeks of the widespread transition from face-to-face classes to emergency remote teaching in the U.S. 
The research questions guiding this study are the following:

- How have institutions provided continuity of education in the early stages of the COVID19 pandemic?

- What techniques are faculty using to deliver instruction online and what modifications have they made to their teaching practices?

- What would be of most assistance to institutions and faculty at this time?

\section{Methods}

The survey was conducted by Bay View Analytics in partnership with the Online Learning Consortium (OLC), WICHE Cooperative for Educational Technologies (WCET), University Professional and Continuing Education Association (UPCEA), Canadian Digital Learning Research Association (CDLRA), and Every Learner Everywhere, with the support of underwriter Cengage, and media support by Inside Higher Ed (IHE). All partners helped disseminate the survey to administrators and faculty across the U.S.; however, only the research team had exclusive access to the data. The research team was solely responsible for the survey design and the analysis of the data.

\section{Participants}

In this study, 897 higher education faculty and administrators from the U.S. responded to a survey. Participants represented 672 institutions from 47 states. Participant institutional affiliation was matched to the federal Integrated Postsecondary Education Data System (IPEDS) to retrieve institutional characteristic data allowing for analyses to be conducted by type of institution (National Center for Education Statistics, n.d.-a). No other demographic data was collected.

The largest group of respondents (47\%) were from four-year public institutions, with 36\% from four-year private institutions and 17\% from two-year institutions. Over one-third (36\%) of the respondents were from the largest (over 20,000 total enrollments) institutions, with an additional $37 \%$ from institutions with between 5,000 and 19,999 total enrollments. Only $6 \%$ of the respondents were from institutions with fewer than 500 total enrollments.

\section{Materials}

The survey consisted of questions designed for faculty, questions directed to administrators, and questions appropriate for both groups. There was a total of 14 questions, five of which were only displayed if appropriate based on a respondent's prior responses. Faculty were presented with a maximum of nine questions and administrators with a maximum of nine. Since many academics have both teaching and administrative responsibilities, respondents were asked to select their primary role and were only presented with questions for that role. Where appropriate, questions included an 'other' response where the respondent could provide their own detailed answer. Administrators were asked questions pertaining to the extent to which courses had transitioned from in-person classes to an online mode of delivery, how in-person classes were being moved online, and what type of assistance they needed at the institutional level during this transition. Faculty were asked about their experiences with online learning prior to the pandemic, course transitions, kinds of assistance that would be of assistance to them, course modifications 
that they needed to do for transitioning their courses online, and types of teaching techniques that they were using in their newly-developed courses.

The median time it took participants to complete the survey was 4.6 minutes among all respondents and 2.5 minutes for those who choose not to respond to the two optional open-ended questions.

\section{Procedures}

Data were collected during the period of April 6 through April 19, 2020. The primary distribution of the survey invitations used two mailing lists from Market Data Retrieval (Market Data Retrieval, n.d.). One list included a representative sample of all U.S. higher education teaching faculty (defined as faculty who were teaching at least one course during the current academic year) and the second was a representative sample of relevant academic administrators (e.g., provosts, deans, department heads). This primary distribution was augmented by announcements and invitations from several of the partner organizations, including the survey link in mailings or newsletters. Some organizations posted the survey invitation to their social media channels (e.g., Twitter, Facebook) and these invitations were further disseminated by other individuals through typical social media activities (e.g., retweeting, reposting, etc.).

All data were checked for completeness, missing values, or erroneous codes. All responses entered as 'other' were reviewed to determine if they should also be coded as one of the fixed responses. The only required question for the survey was that of the role of the respondent (faculty or administrator), so respondents could skip any question or portion of a question. Very few respondents skipped questions, but all surveys where less than three-quarters of the eligible questions were not completed were deleted from the analysis.

Potential participants were provided the option to include their email to receive a copy of a final summary report. Email addresses were separated from the rest of the data prior to any analyses and were deleted once final reports were emailed. To ensure further confidentiality and anonymity, results are presented in aggregate and summary statistics.

\section{Limitations and Delimitations}

This study faces a number of limitations. First, the results of the study rely on self-reported data. Second, because the data were gathered via multiple recruitment approaches (e.g., mailing list, social media), if certain populations are over- or under-represented in certain spaces, the final sample may over- or under-represent those populations. However, because the source of each survey response (direct mail or through a partner newsletter or mailing) was known, the pattern of responses for the supplemental survey outreach by partners was compared to that of the primary direct mail sample to ensure that the addition of these respondents was not biasing the overall pattern of results. Third, all survey responses were linked to the federal IPEDS data and the characteristics of respondent's institutions were compared to the national distribution. The range of responding institutions was a good match for the national pattern with two exceptions: for-profit institutions and the very smallest institutions (those with under 500 total students) were not well represented in the sample. 


\section{Results}

The responses by faculty and administrators were analyzed broadly and by institution type and size. Findings were consistent across different types of institutions and different sizes of institutions. The results were also consistent regardless of whether the institution offered online programs or courses prior to COVID-19.

\section{Current Status}

Administrators and faculty were asked about their current situation. Specifically, all respondents were asked to indicate whether their institution was operating as usual, whether some or all of their in-person classes had been (or were about to be) transitioned to an online environment, whether in-person classes were canceled or suspended, or another option that was not listed. The vast majority of administrators (89\%) reported that their institution had rapidly transitioned to emergency remote teaching. Administrators that fell into the remaining 11\%, reported a variety of reasons as to why they were not employing emergency distance classes such as: already being a fully online institution, their institution was located in an area of the country where stay-at-home orders were not in place, they were working on a different schedule so the term was already complete, or the nature of their instruction was specialized and not possible to replicate online. There was little difference among types of institutions: Most four-year public institutions (93\%) two-year institutions (91\%), and four-year private institutions (87\%) transitioned to emergency remote teaching. Similarly, the majority of faculty $(76 \%)$ reported that some or all of their in-person classes had transitioned to an online mode of delivery, with most of the remaining faculty respondents reporting that they were either continuing operations as usual (e.g., continuing to teach classes that were already online pre-COVID-19), that in-person classes had been suspended or canceled, or that they were not teaching this semester and the transition was not applicable to them.

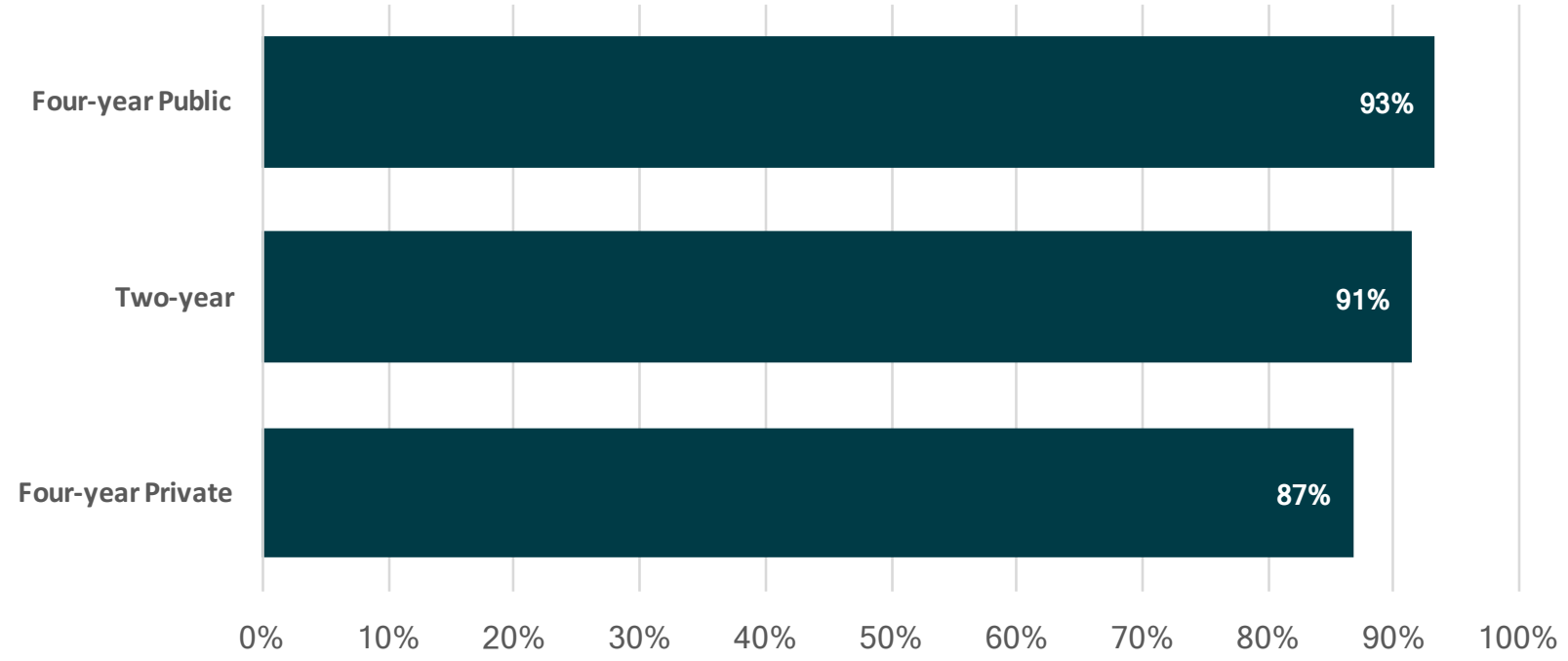

Figure 1. Percentage of Administrators Reporting That Some or All of the Institution's Classes Transitioned to Online.

Additionally, administrators were asked how in-person classes had been moved online. Almost all administrators (97\%) reported that their institution had some faculty with no prior online teaching experience who were now delivering instruction online. Roughly half of the 
administrators surveyed (49\%) reported having faculty at their institution with previous online teaching experience who were delivering courses online following the transition. Very few administrators reported that their institution was receiving assistance in transitioning to an online delivery format from other institutions (3\%), from an industry partner (4\%), or from an association (1\%). The survey question had the option for administrators to leave a comment that described further strategies that were being employed as classes were being moved online. Most commonly, administrators commented that internal supports were being used to facilitate the transition including the use of instructional designers, support from digital learning centers, and mentorship by faculty with online teaching experience. These results were similar regardless of the type of institution.

\section{Faculty Experiences}

To better understand how remote teaching was being conducted, faculty were asked a series of questions about their practices and approaches during this time. To situate their experiences in context, faculty were first asked what kinds of the kinds of experiences that they had with online learning prior to COVID-19. There were a wide variety of experiences reported including having taught an online course. In addition, there were multiple other experiences reported such as taking an online course, teaching or developing hybrid courses, completing doctoral work online, completing training or professional development for teaching online, teaching or mentoring others to teach online, and regular use of their institution's Learning Management System (LMS) or other online platforms when facilitating in-person classes. For this analysis, we were interested in differences in approaches between faculty who had previously taught online and those that had not.

More than half of faculty members (56\%) reported that they were using new teaching methods following the transition to an online setting. Two-thirds of faculty with no teaching experience and half of faculty with previous online teaching experience reported using new teaching methods.

No online teaching experience

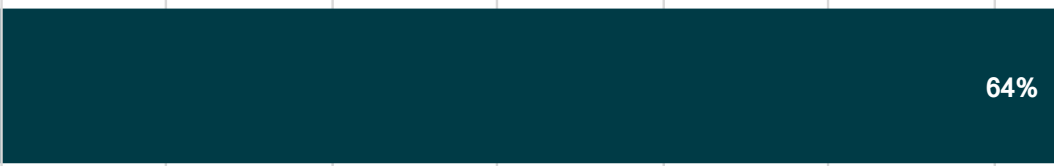

Taught online

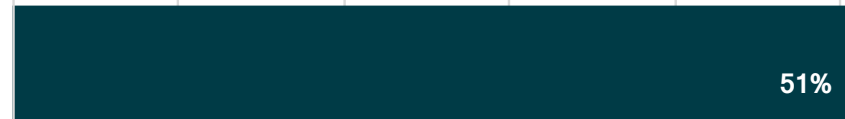

$0 \%$

$10 \%$

$20 \%$

$30 \%$

$40 \%$

$50 \%$

$60 \%$

$70 \%$

Figure 2. Percentage of Faculty Reporting That They Used New Teaching Methods in the Courses That They Transitioned Online by Their Previous Online Experience.

To probe further into the use of new methods to faculty engaged in remote teaching, we asked a series of questions. First, we asked faculty to select from a predetermined list the kinds of techniques they were using (Figure 3). Over two-thirds of faculty reported using three or more of the listed techniques. Distribution of materials via the institution's Learning Management System 
(LMS) and the use of video technologies were the predominant techniques used by the majority of faculty following the transition to emergency remote teaching. A higher proportion of faculty reported using synchronous video (80\%), compared to asynchronous (prerecorded) lectures (65\%) and pre-recorded video from external sources (51\%). A minority of faculty also reported using techniques such as chats using institutional software (24\%) and social media (12\%). Faculty that selected "other" as a response commented that they have used techniques such as apps for learning and communication, email, phone conversations with students, a packaged curriculum, and mailing physical materials to students.

Distribution of material via institution's Learning Management System

Synchronous video (Zoom, GoToMeeting, Google Hangouts, etc.)

Asynchronous recorded video of lectures

Pre-recorded videos from external sources (YouTube, etc.)

Institutional conference/chat function

Other

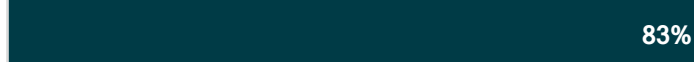

$80 \%$
$51 \%$

\section{$24 \%$}

$14 \%$

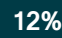

$65 \%$

$\begin{array}{llllllllll}0 \% & 10 \% & 20 \% & 30 \% & 40 \% & 50 \% & 60 \% & 70 \% & 80 \% & 90 \%\end{array}$

Figure 3. Percentage of Faculty Reporting Which Teaching Techniques They Used in Classes Moved Online.

I changed the kinds of assignments or exams I am asking students to do

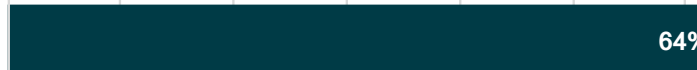

I (or my institution) allowed students the option to choose pass/fail instead of A-F grades for this semester

I lowered my expectations about the amount of work that my students will be able to do

I dropped some assignments or exams

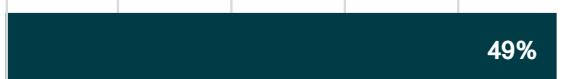
students will be able to do
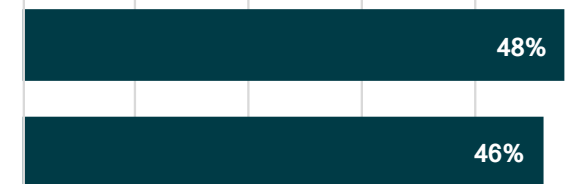

I dropped some of the readings that I was originally asking students to do

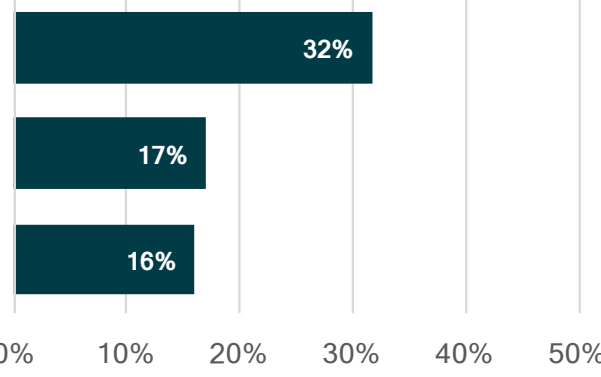

Figure 4. Percentage of Faculty Reporting What Changes They Made to Their Classes Made Moving Them Online. 
We also asked faculty what modifications they made to their curriculum or teaching practices in the classes that they had moved to an online environment: $93 \%$ of faculty made at least one modification to their teaching practice. Roughly two-thirds of faculty reported changing the kinds of assignments or exams that they were asking students to do. Just under half of faculty reported that students were given the option to choose pass/fail grades instead of A through F grades, that they lowered their expectations about the amount of work they expected students to do, or that they eliminated some assignments or exams. Roughly one-third of faculty reported reducing their expectations regarding the quality of student work. Faculty that selected "other" as a response (16\%) made comments about additional modifications including providing more resources and time to students, making situationally appropriate adaptations to accommodate student needs, changing their assessment approach or the weight of certain assignments, and lowering their expectations about their own teaching.

\section{Types of Assistance Needed}

Faculty and administrators were asked about general assistance they might have needed during this time, and administrators were specifically asked about their need for policy assistance. A minority of administrators (32-40\%) identified a need for the policy assistance items listed in Figure 5.

When administrators and faculty were asked what types of general assistance, if any, would be valuable to them, increasing support for students was the top concern for both. Over half of administrators and faculty also identified the need to provide faculty with best practices for working and teaching from home. Some administrators also provided open-ended responses with comments about what other options would be helpful for them. Suggestions included sharing of plans for the 2020 fall semester among institutions, help with developing viable replacements for previously hands-on learning activities, and support with helping faculty transition to working online and providing technology to students.

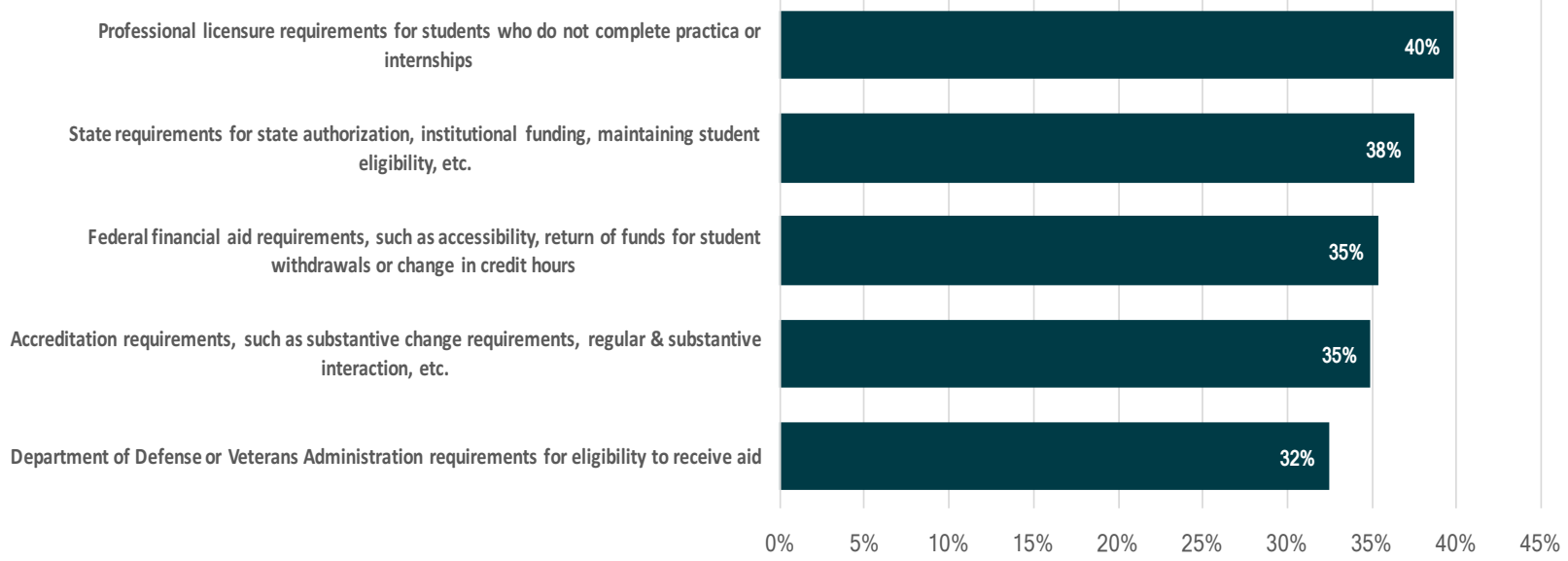

Figure 5. Percentage of Administrators Reporting What Policy Assistance Would Be Most Helpful for Their Institutions. 


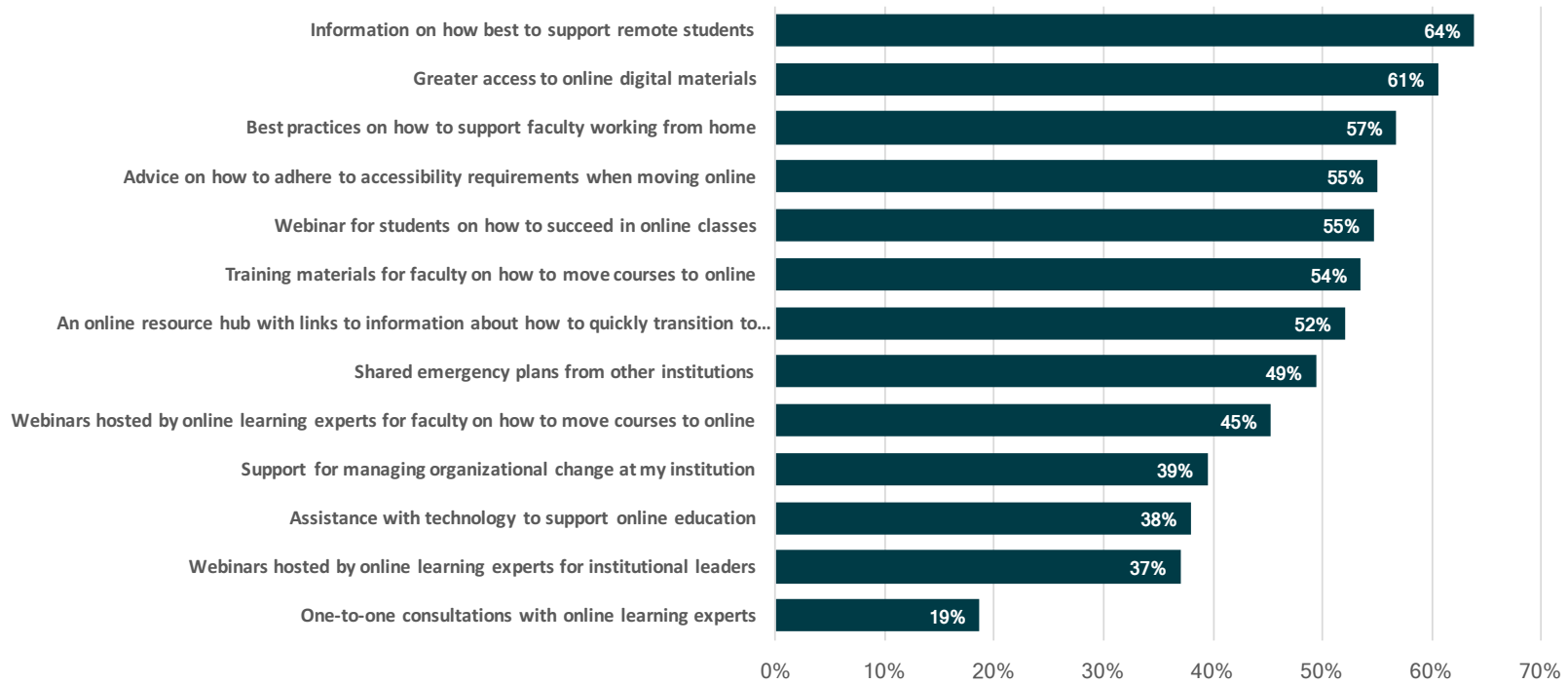

Figure 6. Percentage of Administrators Reporting What Assistance Would Be Most Helpful for Their Institutions.

Faculty were provided with a similar list of options and asked what types of assistance would be helpful to them during the rapid transition to remote teaching. As reflected by the top two responses, faculty were most concerned with student support: an equal number of faculty $(58 \%)$ reported that information on how to best support remote students and a webinar designed for students on how to succeed in online educational settings would be helpful. Additionally, roughly one-half of faculty respondents reported that it would be helpful to have greater access to online digital materials $(53 \%)$ and information on best practices on how to work and teach from home $(53 \%)$. Almost half of faculty respondents indicated that it would be of assistance to have access to an online resource hub with link to information about how to quickly transition to online learning (48\%), advice on adhering to accessibility requirements (46\%), and assistance with technology $(44 \%)$.

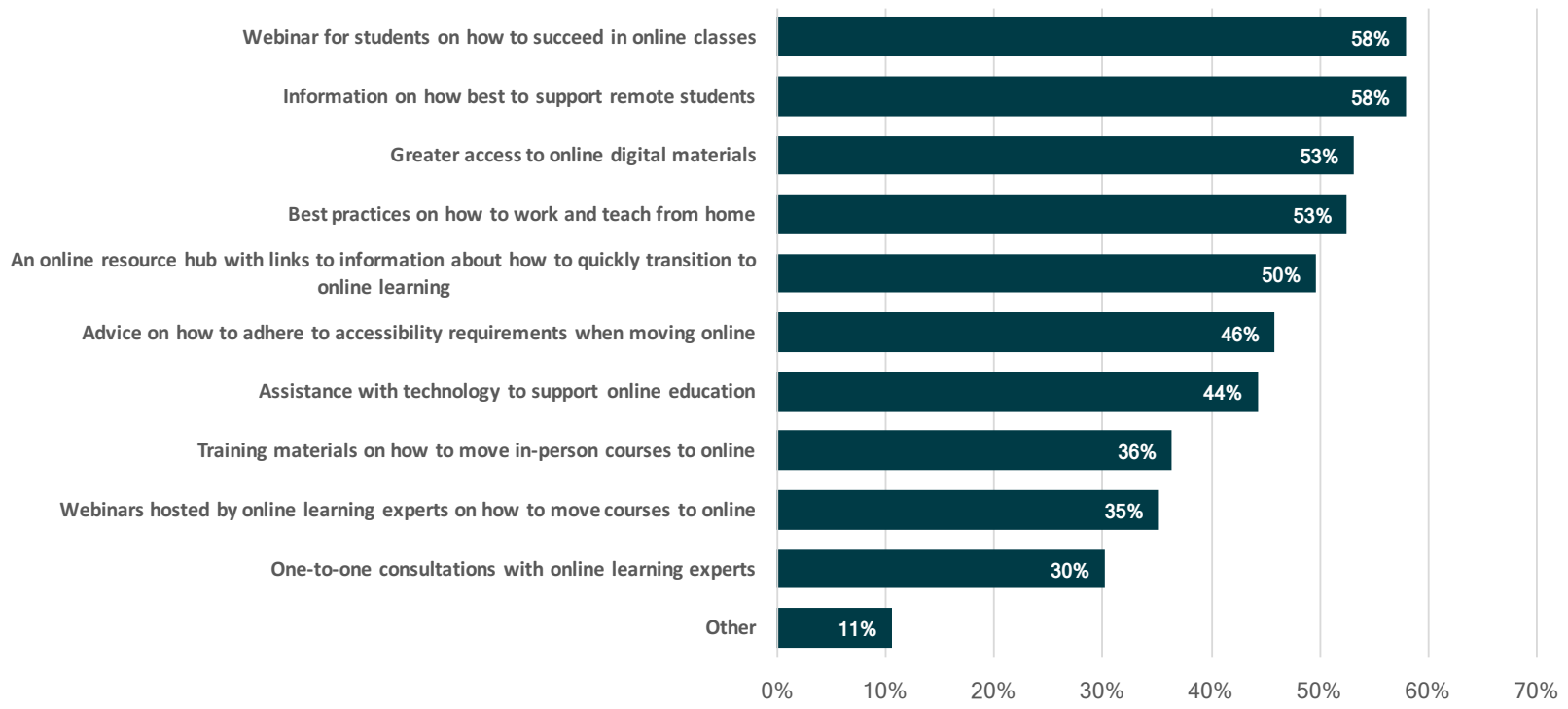

Figure 7. Percentage of Faculty Reporting What Assistance Would Be Most Helpful. 
The faculty respondents who left an open-ended comment suggesting other options that would be of assistance mentioned a need for more time to adjust to the demands of emergency remote teaching, peer support, and mentorship, having a plan for if a student or faculty member becomes ill, teaching strategies for previously hands-on subjects, subject-specific advice for teaching online, access to appropriate technology for themselves and students, and support for coping with acute stress. Several faculty also stated a need for guidance on how to work from home with babies and small children.

\section{Discussion and Implications}

These findings provide a snapshot in time describing administrator and faculty experiences during a tumultuous period that required rapid responses and transitions. In this section, we discuss these results and expand on implications they may have for future practice and research.

\section{Care and Concern}

First, we urge readers to avoid viewing the changes that faculty made to their courses in the middle of the pandemic as criticisms of faculty and their teaching. The changes that the majority of the faculty made to their courses should be viewed not only as necessary, but as steps to support, care for, and enable students to succeed. Whether enacted by individual faculty, departments, or institutions writ large, changes that faculty reported making to their courses (e.g., lowering expectations) aimed at alleviating anxiety and stress, and ultimately supporting students. To put this further in context: at the end of the survey, participants were given the option of leaving an open-ended comment about any concerns they had. While we did not perform a formal analysis of these comments, a large volume of faculty respondents expressed feelings of stress and anxiety. Thus, amidst their own feelings of anxiety and stress, a large number of faculty sought to support their students, oftentimes by being responsive to student needs and engaging with progressive educational practices (e.g., ungrading, eliminating unnecessary work) that center students, and reflect a broader conversation that highlights the need and value of such practices. While this study suggests the presence of this environment of care and concern, future research may provide much more insight into this area. Research specifically investigating how faculty, staff, administrators, and students cared and supported one another during this difficult time may shed light on valuable practices that may be worthwhile to continue enacting. Such research may also investigate individuals' lived experiences but also focus on various other aspects of interest, such as what role class discussions, Zoom sessions, or the elimination of assignments may have offered in terms of emotional support (see Lorenzo, 2008).

\section{The (Un)sustainability of Emergency Remote Teaching}

While emergency remote teaching enabled many students to continue the spring semester amidst the pandemic, this form of education is not a viable long-term solution. Going forward, institutions need to develop sustainable educational plans that can withstand the challenges and unknowns of the ongoing pandemic.

As institutions work to make decisions regarding the fall semester of 2020, plans and contingency plans ought to consider good practices that the field of distance and online learning recommends. Given the unpredictability of the COVID-19 pandemic, it is likely that some form of online and hybrid models of learning will be the most viable options for course delivery for the foreseeable future. Our results indicate that online instruction in the early weeks of the pandemic 
was more characteristic of emergency remote teaching as defined by Hodges et al. (2020) than online learning. For example, regardless of whether they had previous online teaching experience, at least half of faculty respondents reported using new teaching methods. Almost all faculty (93\%) reported making some type of modifications to their teaching practices (e.g., reduced workload for students and lowered expectations regarding the quality of student work). Thus, the impetus is on institutions to equip faculty and students with the necessary skills and resources to teach and learn effectively in online and blended settings that align with health officers' recommendations.

Our survey found that the majority of faculty respondents wanted more information on how to best support remote students as well as best practices for themselves as they work and teach from home. Preparing faculty to teach in online and blended modes will increase the likelihood of quality online educational experiences. We recommend that institutions deploy online professional development opportunities for faculty. These opportunities should not be limited to the use of tools and online learning checklists. Rather they should also emphasize pedagogy, assessment, and the different kinds of support that varied learners need to succeed. Although research on best practices for training faculty to teach online during times of disruption is scant, Tull et al. (2017) suggested establishing virtual communities of practice to reduce reliance on both face-to-face workshops and one-to-one technical support. The majority of research participants indicated that the type of training that would be most helpful for them was having access to an online resource hub with links to information about how to quickly transition to online learning. More information and support on how to continue to teach online, or how to transition between online and in-person classes in response to changing conditions, is necessary not just for the fall but beyond.

Nevertheless, faculty professional development needs to be supplemented by systemic actions and support structures. A successful online and digital learning approach requires an ecological approach and should not solely rely on individual faculty members. To this end, institutions may need to consider how other professionals might support the development of online and blended courses (e.g., instructional designers), what kinds of remote support services might be needed for by students, and how certain services (e.g., libraries) may need reorganization to support teaching and learning. In other words, while professional development is important, there is a need for systemic support to launch and sustain new forms of teaching and learning that may be required, and these supports may be needed not solely at the institutional level but also at the state level as well. Significantly, this issue will impact some institutions more than others, as some may already have some of these structures in place, and some may face more/less financial and resource pressures than others. This may be an area for future investigation, as researchers could probe issues around online learning preparedness, faculty development, inequities across institutions, institutional responses, and so on.

\section{Student Support}

Past research highlighted the importance of maintaining an awareness of student socioemotional needs and inequities when developing online offerings (Czerniewicz et al., 2019; Lorenzo, 2008). In our study, the majority of both faculty (57\%) and administrators (64\%) identified increasing support for students as the top need in terms of assistance. When developing a strategy for continued online learning, or a contingency plan for shifting back to an online environment if in-person classes are being considered, conducting a needs assessment of students is paramount. Do all students have access to the requisite technology to learn effectively online? Are resources available to students to help them develop strategies for success in online learning 
environments? Do faculty have the knowledge and resources to support students as they learn remotely?

\section{Potential for Positive Change}

While rapidly pivoting from in-person to online course delivery on a mass scale was challenging and stressful, it is important to recognize that this was not only an amazing feat, but one that highlights the resiliency of higher education. The magnitude of this transition goes well beyond any previous change in U.S. higher education. According to the most recent IPEDS data (National Center for Education Statistics, n.d.-b.) there were a total of 19,865,281 students enrolled in U.S. degree-granting institutions of higher education in the fall of 2018. Of these students, $16,592,064$ were taking all or some of their courses on campus and were, therefore, a potential candidate for the emergency transition to online learning. The current data do not allow for a precise count of the number of students that were impacted, but even the most conservative estimate would put this number over 10 million. Likewise, the most recent IPEDS count of the number of higher education faculty is 1.5 million (National Center for Education Statistics, 2020). We do not know the exact number of faculty who had to make this transition; however, even accounting for those teaching exclusively online, at institutions that were not impacted, or teaching courses that were canceled instead of transitioned, a fair estimate would be that between 750,000 and a million faculty were involved in some way in making this emergency transition. While the higher education sector is sometimes described as slow and divorced from society, it rapidly developed approaches for instructional and learning continuity and iterated over time. The question that we now need to turn to is the following: how do we create resilient and stable institutions that serve our societies and our futures?

\section{Conclusion}

The rapid transition from in-person to online delivery that the higher education sector experienced differed from a planned online learning experience; even experienced online faculty used new teaching methods to cope with the challenges presented due to this mass-scale pivot. Needs that emerged during the transition to emergency remote teaching should inform strategies for student and faculty support as a plan, or contingency plan, for online instruction is developed for the 2020 fall semester. How to develop long-term online learning strategies is an important issue that institutions need to address to deliver sustainable and high-quality education throughout the duration of the pandemic. Further, strategies implemented now can be built upon and hold the potential to increase institutional resilience in the future. 


\section{Acknowledgments}

Good research is a collaborative effort, with the current project relying on multiple organizations and individuals. Thanks go to Hester Tinti-Kane at Cengage for setting the project in motion and to Tricia Donovan at the Canadian Digital Learning Research Association (CDLRA), Robert Hansen at University Professional and Continuing Education Association (UPCEA), and Jessica Rowland Williams of Every Learner Everywhere for bringing their organizations on board and working so well with the entire team. Russ Poulin brought the WICHE Cooperative for Educational Technologies (WCET) into the fold and provided critical questions about policy alternatives. Jennifer Mathes and Jean Simmons from the Online Learning Consortium were instrumental in building the partnership, coordinating communications, and leading the outreach effort. Finally, I. Elaine Allen, Julia Seaman, and Nate Ralph of Bay View Analytics were critical in getting the project off the ground and in conducting a detailed analysis of the hundreds of open-ended responses. 


\section{References}

Ayebi-Arthur, K. (2017). E-learning, resilience and change in higher education: Helping a university cope after a natural disaster. E-learning and Digital Media, 14(5), 259-274.

Baker, V. L. (2020, March 25). How colleges can better help faculty during the pandemic. Inside Higher Ed. https://www.insidehighered.com/views/2020/03/25/recommendations-howcolleges-can-better-support-their-faculty-during-covid-19

Bates, T. (2020, April 7). What should we be doing about online learning when social distancing ends? Online Learning and Distance Education Resources. https://www.tonybates.ca/2020/04/07/what-should-we-be-doing-about-online-learningwhen-social-distancing-ends/

Beebe, M. (2010). E-learning in Afghanistan. http://erfaned.com/wpcontent/uploads/2018/03/E_Learning_Afg_Maria.pdf

Burke, L. (2020, April 24). The big 'if.' Inside Higher Ed. https://www.insidehighered.com/news/2020/04/24/colleges-lay-groundwork-fall-orwithout-pandemic

Czerniewicz, L., Trotter, H., \& Haupt, G. (2019). Online teaching in response to student protests and campus shutdowns: Academics' perspectives. International Journal of Educational Technology in Higher Education, 16(43), 1-22. https://link.springer.com/content/pdf/10.1186/s41239-019-0170-1.pdf

DePietro, A. (2020, April 30). Here's a look at the impact of coronavirus (COVID-19) on colleges and universities in the U.S. Forbes.

https://www.forbes.com/sites/andrewdepietro/2020/04/30/impact-coronavirus-covid-19colleges-universities/\#723e4c3c61a6

Fain, P. (2020, April 29). The evolving fall picture. Inside Higher Ed. https://www.insidehighered.com/news/2020/04/29/growing-number-colleges-announceintent-reopen-fall

Govindarajan, V., \& Srivastava, A. (2020, March 31). What the shift to virtual learning could mean for the future of higher ed. Harvard Business Review. https://hbr.org/2020/03/whatthe-shift-to-virtual-learning-could-mean-for-the-future-of-higher-ed

Grajek, S. (2020, April, 3). Educause COVID-19 quickpoll results: Help for students. Educause Review. https://er.educause.edu/blogs/2020/4/educause-covid-19-quickpoll-results-helpfor-students

Hodges, C., Moore, S., Lockee, B., Trust, T., \& Bond, A. (2020, March 27). The difference between emergency remote teaching and online learning. Educause Review. https://er.educause.edu/articles/2020/3/the-difference-between-emergency-remoteteaching-and-online-learning

Judy, B. (2020, March 23). Thoughtfulness in a pandemic. Educause Review. https://er.educause.edu/blogs/2020/3/thoughtfulness-in-a-pandemic

Lorenzo, G. (2008). The Sloan semester. Journal of Asynchronous Learning Networks, 12(2), 540. https://files.eric.ed.gov/fulltext/EJ837474.pdf 
Market Data Retrieval. (n.d.). Catalogs. https://mdreducation.com/catalogs/

Morgan, T. (2020, March 10). Online teaching with the most basic of tools-email. Explorations in the Ed Tech World. https://homonym.ca/published/online-teaching-with-the-mostbasic-of-tools-email/

National Center for Education Statistics. (n.d.-a). Integrated postsecondary education data system (IPEDS). https://nces.ed.gov/ipeds/

National Center for Education Statistics. (n.d.-b). The condition of education. https://nces.ed.gov/programs/coe/

National Center for Education Statistics. (2020, May). Characteristics of postsecondary faculty. The Condition of Education. https://nces.ed.gov/programs/coe/indicator_csc.asp

Reed, M. (2020, April 29). Looking ahead, faculty edition: How are people preparing for fall classes? Inside Higher Ed. https://www.insidehighered.com/blogs/confessionscommunity-college-dean/looking-ahead-faculty-edition

Swartz, B.C., Gachago, D., \& Belford, C. (2018). To care or not to care-reflections on the ethics of blended learning in times of disruption. South African Journal of Higher Education 32(6), 49-64.

Tull, S., Dabner, N., \& Ayebi-Arthur, K. (2017). Social media and e-learning in response to seismic events: Resilient practices. Journal of Open, Flexible, and Distance Learning, 21(1), 63-76.

UNESCO. (2020, March 19). Half of world's student population not attending school: UNESCO launches global coalition to accelerate deployment of remote learning solutions. https://en.unesco.org/news/half-worlds-student-population-not-attending-school-unescolaunches-global-coalition-accelerate

Veletsianos, G., \& Kimmons, R. (2020, April 6). What (some) students are saying about the switch to remote teaching and learning. Educause Review. https://er.educause.edu/blogs/2020/4/what-some-students-are-saying-about-the-switch-toremote-teaching-and-learning 